\title{
Health service utilisation associated with chronic breathlessness: random population sample
}

\author{
David C. Currow ${ }^{1,2}$, Sungwon Chang ${ }^{1}$, Magnus Ekström $\mathbb{B}^{1,3}$, Ann Hutchinson ${ }^{2}$, Tim Luckett $^{1}$, \\ Slavica Kochovska ${ }^{1}$, Phillipa Hay ${ }^{4}$, Stephen Touyz ${ }^{5}$, Eleonora Dal Grande ${ }^{6}$ and Miriam J. Johnson ${ }^{1,3}$
}

${ }^{1}$ IMPACCT, Faculty of Health, University of Technology Sydney, Ultimo, NSW, Australia. ${ }^{2}$ Wolfson Palliative Care Research Centre, Hull York Medical School, University of Hull, Hull, UK. ${ }^{3}$ Dept of Clinical Sciences, Division of Respiratory Medicine and Allergology, Lund University, Lund, Sweden. ${ }^{4}$ Translational Health Research Institute, School of Medicine, Western Sydney University, Penrith South, NSW, Australia. ${ }^{5}$ School of Psychology, University of Sydney, Camperdown, NSW, Australia. ${ }^{6}$ University of Adelaide, Adelaide, SA, Australia.

Corresponding author: David C. Currow (David.Currow@uts.edu.au)

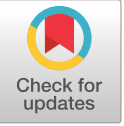

This version is distributed under the terms of the Creative Commons Attribution NonCommercial Licence 4.0. For commercial reproduction rights and permissions contact permissions@ersnet.org

This article has supplementary material available from openres.ersjournals.com

Received: 23 June 2021 Accepted: 4 Aug 2021

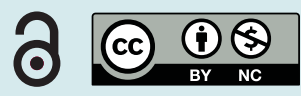

Shareable abstract (@ERSpublications)

Worsening self-reported severity of chronic breathlessness is strongly associated with increases in general practice and emergency department use and inpatient admissions, after controlling for age, sex, level of education, rurality and body mass index https://bit.ly/3sa9knG

Cite this article as: Currow DC, Chang S, Ekström M, et al. Health service utilisation associated with chronic breathlessness: random population sample. ERJ Open Res 2021; 7: 00415-2021 [DOI: 10.1183/ 23120541.00415-2021].

\section{Abstract}

Background Most health service utilisation studies are of people with specific diagnoses or demographic characteristics, and rarely of specific chronic symptoms. The aim of this study was to establish whether population-level health service utilisation increases in people with chronic breathlessness.

Methods A cross-sectional analysis was carried out of the South Australian Health Omnibus Survey 2017, a multi-stage, clustered area, systematic sampling survey of adults where questions are administered faceto-face in respondents' homes. Self-report of health service utilisation in the previous 3 months (medical consultations, emergency department, hospital admission), chronic breathlessness (severity, duration, modified Medical Research Council (mMRC) breathlessness scale) and demographic data were used to predict self-reported health service utilisation.

Results A total of 2898 people were included (49.0\% male; median age 48.0 years (IQR 32.0-63.0); 64.1\% educated beyond school; $55.4 \%$ in work; $73.5 \%$ had outpatient contact; $6.3 \%$ had a hospital admission in the previous 3 months). Chronic breathlessness (mMRC $\geqslant 1$ ) was reported by $8.8 \%$ of respondents. In bivariable analyses, people with greater contact with health services were older, and a higher proportion were overweight/obese and had more severe chronic breathlessness. In multivariable analyses, chronic breathlessness and older age were positively associated with outpatient care and inpatient care, and people with chronic breathlessness were hospitalised for longer (incidence rate ratio 2.5; 95\% CI 1.4-4.5).

Conclusion There is a significant association between worse chronic breathlessness and increased health service utilisation. There is a need for greater understanding of factors that initiate contact with health services.

\section{Introduction}

Most health service utilisation studies are built around people with specific diagnoses (e.g. COPD) [1] or populations with specific demographic characteristics (e.g. age categories). Few studies refer to chronic symptoms, especially without recruiting through health services. This current study explores health service utilisation at the population level (irrespective of the underlying aetiology) of people living with chronic breathlessness from any cause (cardio-respiratory, neurodegenerative, neoplastic) [2] without using contact with health services as the recruiting mechanism.

Health service access can be considered from a number of perspectives including from a behavioural viewpoint [3, 4]: 1) predisposing factors, typically demographic characteristics (e.g., age, sex); 2) access 
(e.g., income, access to a regular general practitioner); and 3) need factors (perceived (e.g., quality of life, symptoms), evaluated (e.g., diagnoses)), which are the most immediate reasons for health services use.

Chronic breathlessness is strongly associated with impairment of many aspects of personhood and wellbeing including prognosis [5], functional status [6], physical and mental domains of quality of life [7], activities of daily living including self-care [6] and sexual activity [8]. Depression and anxiety increase as chronic breathlessness worsens [6,9]. As daily breathlessness gets worse, people give up more and more activities in order to reduce provoking the symptom, limiting social interactions [10, 11]. Clinically, the severity and impact of chronic breathlessness may be under-recognised and, even when recognised, under-treated [12-14].

Acute-on-chronic breathlessness [12] is often a catalyst for unplanned healthcare contact [15, 16], including primary care [17] (with increasing likelihood of referral to hospital) and, through ambulance conveyances to the emergency department (ED), where one in five conveyances are for people experiencing acute-on-chronic breathlessness [18]. Breathlessness in adults accounts for one in 20 of all ED presentations $[18,19]$, one in 10 admissions to general wards from the ED and one in five admissions to intensive care from the ED [19]. Breathlessness is associated with appreciable mortality in the ED $(0.6 \%)$ and in breathlessness-related hospital admissions (5.0\%), increasing to $7.9 \%$ in people $>75$ years of age [20, 21]. Conversely, one-third of people presenting to the ED with acute-on-chronic breathlessness can be discharged home directly [18, 19], suggesting some attendances could be avoided with improved community care or self-management. In Australia, COPD is the disease most commonly associated with preventable hospitalisations for men [22].

The present study aims to investigate patterns of health service utilisation in people who self-report the subjective sensation of chronic breathlessness (compared to people who do not report its presence) in a random sample of community-dwelling adults, in order to inform our understanding of health service contact. This cohort is drawn directly from the community, not through contact with health services.

\section{Methods}

\section{Survey design}

This study analyses the 2017 South Australian Health Omnibus Survey (HOS) [23, 24], which was an annual, cross-sectional, multi-stage, clustered area, systematic sampling survey. It was conducted by a commercial research organisation, with de-identified data made available to user-pay researchers. Approximately 200 questions were asked, including a core set of demographic questions.

Data were collected through structured, face-to-face interviews in participants' homes by trained interviewers, lasting 60-90 min as previously detailed [24, 25]. Engagement was therefore independent of health service contact.

\section{Setting and participants}

South Australia is the second least populous Australian state, with a population of 1.73 million (6.9\% of the Australian population; $983482 \mathrm{~km}^{2}$ ), most of whom live in Adelaide, the state's capital [26]. The survey was conducted between September and December 2017, after a pilot survey with 50 community members. A stratified sampling method identified a representative cohort from metropolitan and rural towns with populations of $>1000$.

Two randomisations informed the sampling process: randomly choosing census collector districts (CCD) in which to conduct interviews; and randomly choosing the starting point within each CCD. From this starting point, every tenth property was selected. Sampled properties $(>5000)$ included houses and excluded businesses, properties with other uses, vacant land, hotels, hospitals, caravan parks and aged care facilities. For all households approached, interviewers would return up to five further times if there was no contact at the first visit. Participation rates were calculated on the number of people successfully contacted.

There was one interview conducted in each household with the person aged $\geqslant 15$ years who most recently had a birthday. If that person was unwilling to participate, the household was classified as declining participation.

\section{Data quality}

All data were double entered, with a supervisor following up missing responses by telephone. Additionally, $10 \%$ of each interviewer's respondents were re-contacted to confirm eligibility and ensure 
consistency of responses by re-answering some questions. Data were anonymised before release to researchers.

Data were weighted to the 2016 Estimated Residential Population for South Australia by 5-year age groups, sex, rurality and household size derived from the Australian 2016 Census. Analyses were restricted to participants $\geqslant 18$ years old who answered questions on breathlessness and health service utilisation.

\section{Health service utilisation}

Health service utilisation was assessed in three ways: “Any medical consultations" (none/ $\geqslant 1$ ) and "Frequent medical consultations" $(0-2 / \geqslant 3)$ were assessed with question (1) "In the past 3 months, approximately how many times have you seen/visited/attended a GP or a specialist other than a mental health specialist for your healthcare?". "Any emergency department visits" (none/ $\geqslant 1$ ) were assessed with question (2) "In the past 3 months, approximately how many times have you visited/attended/presented to the ED of a hospital for your healthcare?”. Respondents who indicated that they had visited a general practitioner, a specialist, or attended the ED in the past 3 months were categorised as having "outpatient contact".

Inpatient care was assessed (none/ $\geqslant 1$ ) using question (3) "In the past 3 months, approximately how many times have you been admitted to hospital?”. Of those who reported admission, length of stay was sought.

\section{Chronic breathlessness}

Chronic breathlessness was self-reported using the modified Medical Research Council (mMRC) scale [27], combined with chronicity, consistent with previous analyses: [7, 23, 25, 28] "Thinking back over the last 6 months, have you had an episode of breathlessness that has lasted more than 3 months", with response categories including: $0=$ None; $1=$ "I get short of breath when hurrying on the level or up a slight hill”; 2="I have to stop for breath when walking at my own pace on the level”; $3=$ "I stop for breath after walking 100 metres or after a few minutes on the level"; or 4="I am too breathless to leave the house". The mMRC is reliable, valid and the most commonly used scale for categorising the physical exertion before breathlessness limits ability [27, 29]. Respondents were classified according to the severity of breathlessness (mMRC 0, mMRC 1 and, given numbers, aggregated mMRC 2-4).

\section{Other covariates}

Socio-demographic data were collected on age, sex, birthplace, region of residence, marital status, highest level of education, workforce status and postcode. Postcodes were linked to the Socio-Economic Index for Areas (SEIFA) to derive five equal socioeconomic groups, derived from Australian national census data [30]. Body mass index (BMI; $\mathrm{kg} \cdot \mathrm{m}^{-2}$ ) was calculated from self-reported height and weight given the demonstrated increase in chronic breathlessness as BMI increases. BMI was categorised according to international criteria - not overweight (BMI <25), overweight $(25 \leqslant$ BMI $<30)$ or obese $(\mathrm{BMI} \geqslant 30)$ [31]. As the rate of missing data was low for all variables except BMI (5.9\%), no data were imputed.

\section{Statistical analysis}

Analyses were conducted using SPSS for Windows Version 26.0 (IBM, Chicago, IL, USA, 2011). Respondents' demographic characteristics were compared by health service utilisation (outpatient care, inpatient care, any medical consultations, frequent medical consultations and ED visits) using Fisher's exact test/Pearson's chi-square for categorical variables and Mann-Whitney tests for continuous data. Multiple logistic regression was used to identify variables independently associated with health service utilisation. Those associated in the bivariate analysis with a p-value of $<0.2$ or identified as clinically important from prior studies were considered for multiple logistic regression models. Some variables were excluded in the final model to avoid multi-collinearity and bias that may result from overfitting due to including probable intermediate variables in the causal pathway between chronic breathlessness and health service utilisation [32, 33]. The association between length of stay for those admitted to hospital in the previous 90 days and chronic breathlessness was examined using a negative binomial regression model. Associations were expressed as odds ratios from logistic regression and incident rate ratios from negative binomial regression, with $95 \%$ confidence intervals. A sensitivity analysis was performed for each model using the area under the curve.

\section{Ethics approval and consent}

Approval for the study was provided by the Human Research Ethics Committee of the South Australian Department of Health and the University of Adelaide Human Research Ethics Committee (H-097-2010). Each participant provided informed verbal consent, with continued participation accepted as ongoing consent. 
Results

A total of 2898 people were included; 49.0\% male; median age 48.0 years (IQR 32.0-63.0). About two-thirds were educated beyond school (64.1\%), more than half worked (55.4\%) and three-quarters lived in Adelaide (74.3\%). Nearly three-quarters of respondents had self-reported contact with outpatient care (73.5\%) and 6.3\% with inpatient care in the previous 3 months (table 1). Chronic breathlessness $(\mathrm{mMRC} \geqslant 1)$ was reported by $8.8 \%$ of the respondents (table 1$)$.

In the bivariate analysis, those who had contact with health services (outpatient care, inpatient care, any medical consultation, frequent medical consultations, any ED visits) were older, had a higher proportion of overweight and obese respondents, and experienced more severe chronic breathlessness than those without (table 1; supplementary Table S1). Although the proportion of men with outpatient care (including frequent medical consultations, or any medical consultation) was lower than women, they more frequently had inpatient care. People living in Adelaide had more outpatient care than in non-metropolitan areas.

\begin{tabular}{|c|c|c|c|c|c|c|c|}
\hline & \multicolumn{2}{|c|}{$\begin{array}{l}\text { Outpatient }{ }^{\#} \text { care in the } \\
\text { previous } 3 \text { months }\end{array}$} & \multirow[t]{2}{*}{$\mathrm{p}$-value } & \multicolumn{2}{|c|}{$\begin{array}{l}\text { Inpatient care in the } \\
\text { previous } 3 \text { months }\end{array}$} & \multirow[t]{2}{*}{$\mathrm{p}$-value } & \multirow[t]{2}{*}{ Total } \\
\hline & None & $\geqslant 1$ & & None & $\geqslant 1$ & & \\
\hline Subjects & $770(26.6)$ & $2128(73.4)$ & & $2716(93.7)$ & $182(6.3)$ & & $2898(100)$ \\
\hline Age years, median (IQR) & $41.0(27.0-53.0)$ & $52.1(34.0-66.0)$ & $<0.001$ & $47.0(32.0-62.0)$ & $55.5(39.6-68.0)$ & $<0.001$ & $48.0(32.0-63.0)$ \\
\hline Sex & & & $<0.001$ & & & 0.3 & \\
\hline Male & $468(33.0)$ & $951(67.0)$ & & $1322(93.2)$ & $97(6.8)$ & & $1419(49.0)$ \\
\hline Female & $302(20.4)$ & $1177(79.6)$ & & $1394(94.3)$ & $85(5.7)$ & & $1479(51.0)$ \\
\hline Australia born ${ }^{f}$ & & & 0.5 & & & 0.7 & \\
\hline Yes & $548(26.2)$ & $1541(73.8)$ & & 1955 (93.6) & $134(6.4)$ & & $2089(72.1)$ \\
\hline No & $222(27.5)$ & $585(72.5)$ & & $759(94.1)$ & $48(5.9)$ & & $807(27.9)$ \\
\hline Highest level of education ${ }^{\# \#}$ & & & 0.04 & & & 0.6 & \\
\hline School & $295(28.4)$ & $743(71.6)$ & & $969(93.4)$ & $69(6.6)$ & & $1038(35.9)$ \\
\hline $\begin{array}{l}\text { Trade, apprenticeship, certificate, } \\
\text { diploma/degree or higher }\end{array}$ & $475(25.6)$ & $1381(74.4)$ & & $1743(93.9)$ & $113(6.1)$ & & $1856(64.1)$ \\
\hline Work status & & & $<0.001$ & & & 0.004 & \\
\hline Working full or part-time, self employed & $513(32.0)$ & $1091(68.0)$ & & $1522(94.9)$ & $82(5.1)$ & & $1604(55.4)$ \\
\hline $\begin{array}{l}\text { Not working (home duties, } \\
\text { unemployed, retired, student, other) }\end{array}$ & $257(19.9)$ & $1034(80.1)$ & & $1191(92.3)$ & $100(7.7)$ & & $1291(44.6)$ \\
\hline Living arrangements $^{++}$ & & & 0.003 & & & 0.07 & \\
\hline Married/de facto & $454(24.7)$ & $1382(75.3)$ & & 1709 (93.1) & $127(6.9)$ & & $1836(63.4)$ \\
\hline $\begin{array}{l}\text { Separated, divorced, widowed, } \\
\text { never married }\end{array}$ & $315(29.8)$ & $743(70.2)$ & & $1003(94.8)$ & $55(5.2)$ & & $1058(36.6)$ \\
\hline Region of residence & & & 0.02 & & & 1.0 & \\
\hline Metropolitan & $547(25.4)$ & $1607(74.6)$ & & $2018(93.7)$ & $136(6.3)$ & & $2154(74.3)$ \\
\hline Non-metropolitan & $223(30.0)$ & $521(70.0)$ & & $697(93.7)$ & $47(6.3)$ & & $744(25.7)$ \\
\hline Socioeconomic indexes for area quintile & & & 0.2 & & & 0.2 & \\
\hline 1 (most disadvantaged) & $203(26.8)$ & $554(73.2)$ & & $702(92.7)$ & $55(7.3)$ & & $757(26.1)$ \\
\hline 2 & $139(24.8)$ & $421(75.2)$ & & $515(92.1)$ & $44(7.9)$ & & $559(19.3)$ \\
\hline 3 & $158(29.8)$ & $373(70.2)$ & & $502(94.4)$ & $30(5.6)$ & & $532(18.4)$ \\
\hline 4 & $135(23.9)$ & $431(76.1)$ & & $536(94.5)$ & $31(5.5)$ & & $567(19.6)$ \\
\hline 5 (most advantaged) & $135(28.0)$ & $348(72.0)$ & & $460(95.2)$ & $23(4.8)$ & & $483(16.7)$ \\
\hline Body mass index $(\mathrm{BMI})^{\S \S}$ & & & $<0.001$ & & & $<0.001$ & \\
\hline Not overweight & $354(32.4)$ & $738(67.6)$ & & $1035(94.8)$ & $57(5.2)$ & & $1092(40.0)$ \\
\hline Overweight $^{+}$ & $259(26.7)$ & $710(73.3)$ & & $919(94.8)$ & $50(5.2)$ & & $969(35.5)$ \\
\hline Obese $\S^{\S}$ & $102(15.3)$ & $565(84.7)$ & & $602(90.3)$ & $65(9.7)$ & & $667(24.5)$ \\
\hline mMRC & $<0.001$ & & $<0.001$ & & & $<0.001$ & \\
\hline 0 & $741(28.0)$ & $1902(72.0)$ & & 2496 (94.4) & $147(5.6)$ & & 2643 (91.2) \\
\hline 1 & $27(15.6)$ & $146(84.4)$ & & $158(91.3)$ & $15(8.7)$ & & $173(6.0)$ \\
\hline $2-4$ & $2(2.4)$ & 80 (97.6) & & $62(75.6)$ & $20(24.4)$ & & $82(2.8)$ \\
\hline
\end{tabular}


There was no difference between the region of residence for inpatient care or ED visits. These associations persisted in adjusted models (supplementary Table S2).

In the multivariate analyses, those who were older, female, educated beyond school, living in Adelaide, overweight/obese and with more severe chronic breathlessness were more likely to have accessed outpatient care (supplementary Table S2).

The c-statistics, reflecting strength of association for outpatient care, were (in order of magnitude): age, BMI, sex, chronic breathlessness, region of residence and highest level of education. The odds of frequent medical consultations increased with age, being female, obesity, living in Adelaide and more severe chronic breathlessness (supplementary Table S2). ED visits and inpatient care were associated with increasing age, obesity and severity of breathlessness. Additionally, being male was a factor for inpatient care (supplementary Table S2). For inpatient care, the c-statistics were highest for age, followed by chronic breathlessness. The variables studied accounted for a relatively small proportion of the variation (supplementary Table S2).

The incidence rate ratio for length of stay (LOS) in the negative binomial model indicated that chronic breathlessness (mMRC 2-4) had 2.5 (95\% CI 1.4-4.5) times the length of stay of those with no chronic breathlessness (mMRC 0). The subsequent LOS were higher for people with worse chronic breathlessness with the estimated marginal mean length of stay for chronic breathlessness being: mMRC 0, 3.0 (95\% CI 2.4-3.8); mMRC 1, 4.1 (95\% CI 2.2-7.5) and mMRC 2-4, 7.6 (95\% CI 4.4-13.0) days.

The strong association between severe chronic breathlessness and health service utilisation (outpatient care, inpatient care, frequent medical consultations, any medical consultations and ED visits) remained after adjustment for significant demographic characteristics and BMI (tables 2 and 3). For all aspects of health service utilisation including LOS, chronic breathlessness showed a "dose response" with the proportion increasing as mMRC scores increased (Figure 1).

\section{Discussion}

Three-quarters of respondents in this population sample reported health service contact in the previous 3 months, the majority of which were as outpatients, in keeping with many comparable high-income countries [34]. Men had lower rates of contact with outpatient services than women, but higher rates of hospital admissions, suggesting that the lower rate of primary care contact may be translating into greater severity of clinical presentations - a finding consistent with several previous reports across healthcare [35-37]. One in 11 people (8.8\%) in the general population (without recruiting through health service contact) reported chronic breathlessness. This was associated with increased healthcare utilisation (outpatient and inpatient care, and LOS), with the relationship strengthening with worse breathlessness [38]. This study complements studies that have sought to define associations between health service utilisation and specific diagnoses (rather than symptoms).

In general, our findings are consistent with other studies of the social and clinical determinants of health [39-41], and of health service utilisation by people with breathlessness due to a range of medical conditions [42-44]. The pattern of health service use is likely to reflect the level of respondents' health and therefore needs: poorer in those who are older, less educated, not in employment, single, obese and breathless due to a range of chronic illnesses. In addition to variations in health service availability [45], health service use reflects availability, health status and levels of health literacy, all of which are related to

\begin{tabular}{|c|c|c|c|c|}
\hline \multirow[b]{2}{*}{ mMRC } & \multicolumn{2}{|c|}{ Outpatient ${ }^{\#}$ care OR $(95 \% \mathrm{Cl})$} & \multicolumn{2}{|c|}{ Inpatient care OR $(95 \% \mathrm{Cl})$} \\
\hline & Unadjusted & Adjusted" & Unadjusted & Adjusted $^{+}$ \\
\hline 0 & Ref & Ref & Ref & Ref \\
\hline 1 & $2.1(1.4-3.2)$ & $1.8(1.1-2.9)$ & $1.6(0.9-2.8)$ & $1.4(0.8-2.6)$ \\
\hline $2-4$ & $18.3(4.0-83.6)$ & $9.0(2.0-41.5)$ & $5.5(3.2-9.2)$ & $4.2(2.4-7.4)$ \\
\hline
\end{tabular}




\begin{tabular}{|c|c|c|c|c|c|c|}
\hline \multirow[b]{2}{*}{ mMRC } & \multicolumn{2}{|c|}{$\begin{array}{l}\text { Any medical consultation } \\
\qquad \text { OR }(95 \% \mathrm{Cl})\end{array}$} & \multicolumn{2}{|c|}{$\begin{array}{l}\text { Frequent }^{\#}(\geqslant 3) \text { medical } \\
\text { consultations OR }(95 \% \mathrm{Cl})\end{array}$} & \multicolumn{2}{|c|}{$\begin{array}{l}\text { Any emergency department } \\
\text { visits OR }(95 \% \mathrm{Cl})\end{array}$} \\
\hline & Unadjusted & Adjusted & Unadjusted & Adjusted $^{+}$ & Unadjusted & Adjusted $^{\S}$ \\
\hline 0 & Ref & Ref & Ref & Ref & Ref & Ref \\
\hline 1 & $2.1(1.4-3.3)$ & $1.8(1.1-3.0)$ & $2.4(1.7-3.3)$ & $1.8(1.3-2.6)$ & $1.3(0.8-2.2)$ & $1.0(0.5-1.8)$ \\
\hline $2-4$ & $18.5(4.1-84.7)$ & $9.1(2.0-42.1)$ & $7.2(4.6-11.4)$ & $4.6(2.8-7.5)$ & $4.1(2.4-7.0)$ & $3.6(2.0-6.3)$ \\
\hline
\end{tabular}

social determinants of health, as well as influences such as health beliefs (stigma, self-blame, distrust) and help-seeking behaviours.

Our findings show a clear relationship between health service use and severity of chronic breathlessness. Given the known impact of chronic breathlessness on quality of life (again in a "dose-dependent" manner) [7], the distressing nature of chronic and acute-on-chronic breathlessness $[18,46]$ and prevalence that lasts many years for most people [47], both perceived and evaluated need factors trigger outpatient and inpatient care.

Although there is universal access to primary care in Australia, a greater proportion of women than men contacted these services; the pattern was reversed in hospital admissions. Commonly the first point of contact, outpatient care, has some potential to ameliorate aspects of chronic breathlessness, and all people should be encouraged by their clinician to seek help in primary care in order to overcome the reluctance that some (in particular men) feel about presenting with chronic breathlessness [15], a finding that has previously been described more broadly across healthcare [48]. The importance of a healthcare practitioner who understands the impact of chronic breathlessness, addressing the symptom as well as the underlying pathology, has been described [12]. However, in one study three-quarters of ED attendees due to breathlessness stated they had talked to their general practitioner about their breathlessness [18]; other studies present suboptimal engagement of primary care in chronic breathlessness management, with many patients reporting disappointment with their consultation $[49,50]$ or lack of timely primary care support as a reason to seek emergency hospital care [15]. Lack of identification and assessment of [51], and interventions for, breathlessness in primary care given that patients do present with this symptom [17],

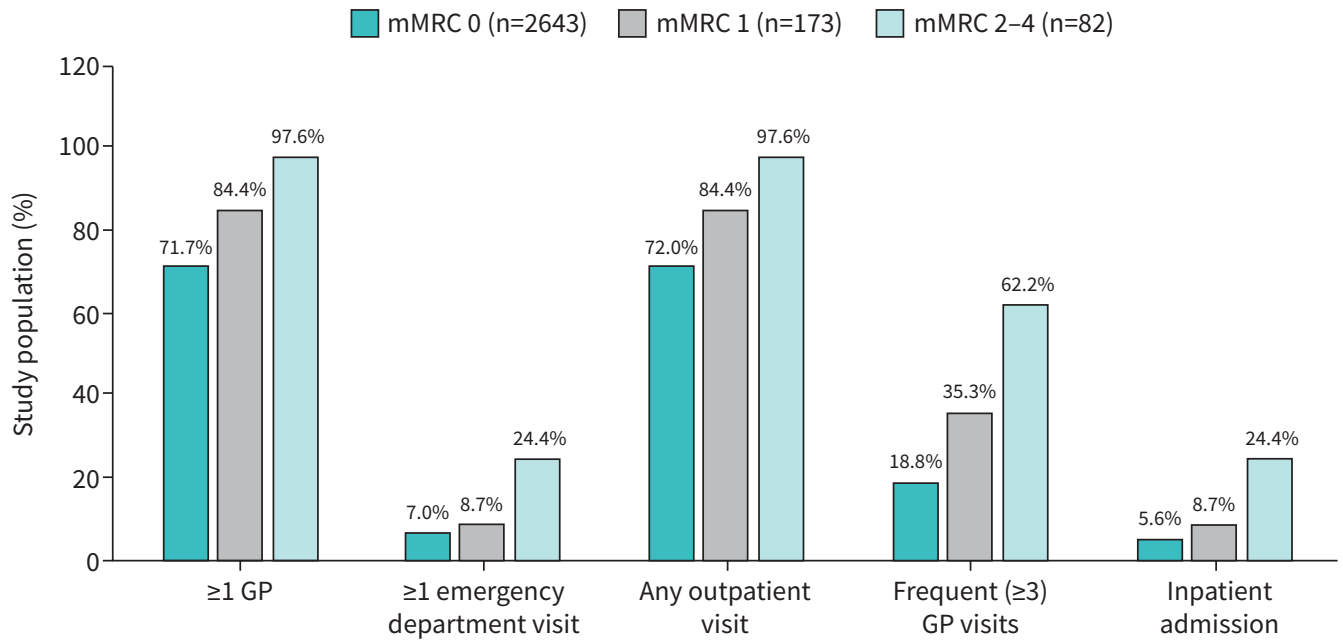

FIGURE 1 Health service utilisation in the previous 3 months by self-reported chronic breathlessness in a random sample of the population of South Australia from face-to-face interviews ( $n=2898)$. mMRC: modified Medical Research Council breathlessness scale; GP: general practitioner. 
represents lost opportunities for evidence-based management, especially for supported self-management strategies with non-pharmacological interventions, which have proven efficacy [52].

\section{Implications for policy and practice}

Identifying people with chronic breathlessness should alert practitioners to the association with the risk of increased future health service utilisation. We need to consider whether that identification should lead to specific contingency planning to try and manage chronic care more effectively.

Given the strong correlation between increasing intensity of breathlessness and use of health service resources, the findings support recent and current initiatives to recognise "chronic breathlessness" as a distinct clinical entity. The delineation of "chronic breathlessness" as a syndrome, proposed in 2017 following an international consensus process [2], would not only increase clinicians' awareness of it (prompting timely, evidence-based treatment), but also help provide an accurate picture of its demand on health services beyond that caused by the underlying condition(s). Similarly, the classification of "chronic breathlessness" as distinct from "acute breathlessness" in the World Health Organisation (WHO) International Classification of Diseases Eleventh Edition (ICD-11) [53] would help to quantify the impact of chronic breathlessness on health service utilisation (including unplanned contact and LOS) as a key explanatory variable for differences seen in health service data but not explained by current codes which do not identify chronic breathlessness. The classification will have implications for wider service mapping, including readmission rates, clinical investigations and prescribing for chronic breathlessness. Higher severity of breathlessness correlates with higher 28-day readmission rates [54]. Recognising chronic breathlessness as a discrete syndrome adequately coded in clinical practice has the potential to create resource efficiencies across health service domains, and prompt more systematic assessment and management. It will ultimately empower patients and their caregivers to acknowledge and disclose in clinical consultations the burden associated with it, enabling clinicians to respond to previously unidentified and unmet needs.

\section{Implications for further research}

We need greater understanding of what generates contact with health services (and whether there are different and predictable reasons for contact with different services (general practice, ED)) and what leads to hospitalisation. These will be important baseline data to determine whether self-management interventions can reduce these rates [55].

Given the impact on LOS demonstrated in this study, delineation of the specific contribution of chronic breathlessness to length of inpatient stay (i.e. hospital admission for the same condition with and without chronic breathlessness) is the next logical study question, again potentially leading to interventions targeting the symptom in addition to the underlying disease.

\section{Strengths and limitations}

This study examines the association (not a causal relationship) of self-reported outpatient care and admission to hospital with the subjective sensation of chronic breathlessness using the mMRC, which reflects the level of exertion before breathlessness supervenes. The study offers a valuable insight into the extent of health service utilisation in the general community for this symptom. Self-reporting healthcare utilisation raises the possibility of incomplete or inaccurate recall. Although we relate our findings to the clinical syndrome of chronic breathlessness, we are unable to state whether or not the respondents were on optimal disease treatment.

Of note, the independent predictors in our final model explained a proportion of the variation indicating, in common with many other studies [4], that significant other influences were not measured. These particularly include factors that should be captured specifically in future population-based studies such as physician-diagnosed conditions that may contribute to chronic breathlessness. Further permission could be sought from people in population-based studies with a positive history to participate in a study where physiological parameters are measured. The application of a behavioural model [3] helps to demonstrate how individual health beliefs and behaviours also influence health service utilisation, and thus this is unsurprising for a multidimensional symptom such as chronic breathlessness.

Provenance: Submitted article, peer reviewed.

Conflict of interest: D.C. Currow is an unpaid member of an advisory board for Helsinn Pharmaceuticals and Specialist Therapeutics, and has consulted to and received intellectual property payments from Mayne Pharma. S. Chang has nothing to disclose. M. Ekström has nothing to disclose. A. Hutchinson has nothing to disclose. 
T. Luckett has nothing to disclose. S. Kochovska has nothing to disclose. P. Hay has nothing to disclose. S. Touyz has nothing to disclose. E. Dal Grande has nothing to disclose. M.J. Johnson has consulted to Mayne Pharma.

Support statement: Funds to conduct this study were drawn from discretionary funds help by the academic teams involved in the collection and analyses of these data.

\section{References}

1 Rennard S, Decramer M, Calverley PMA, et al. Impact of COPD in North America and Europe in 2000: subjects' perspectives of Confronting COPD International Survey. Eur Respir J 2002; 20: 799-805.

2 Johnson MJ, Yorke J, Hansen-Flaschen J, et al. Towards an expert consensus to delineate a clinical syndrome of chronic breathlessness. Eur Respir J 2017; 49: 1602277.

3 Andersen R, Newman JF. Societal and individual determinants of medical care utilization in the United States. Milbank Q 2005; 83: 95-124.

4 Babitsch B, Gohl D, von Lengerke T. Re-revisiting Andersen's behavioral model of health services use: a systematic review of studies from 1998-2011. Psychosoc Med 2012; 9: 11.

5 Nishimura K, Izumi T, Tsukino M, et al. Dyspnea is a better predictor of 5-year survival than airway obstruction in patients with COPD. Chest 2002; 121: 1434-1440.

6 Currow DC, Chang S, Dal Grande E, et al. Quality of life changes with duration of chronic breathlessness: a random sample of community-dwelling people. J Pain Symptom Manage 2020; 60: 818-827.

7 Currow DC, Dal Grande E, Ferreira D, et al. Chronic breathlessness associated with poorer physical and mental health-related quality of life (SF-12) across all adult age groups. Thorax 2017; 72: 1051-1053.

8 Ekström M, Johnson MJ, Taylor B, et al. Breathlessness and sexual activity in older adults: the Australian Longitudinal Study of Ageing. NPJ Prim Care Respir Med 2018; 28: 20.

9 Poulos L, Marks G, Currow D, et al. The prevalence and burden of breathlessness in Australian adults: the National Breathlessness Survey - a cross-sectional, web-based population survey. Respirology 2021; 26 : 768-775.

10 Michalovic E, Jensen D, Dandurand RJ, et al. Description of participation in daily and social activities for individuals with COPD. COPD 2020; 17: 543-556.

11 Kochovska S, Chang S, Morgan DD, et al. Activities foregone because of chronic breathlessness: a cross-sectional, population prevalence study. Palliat Med Rep 2020; 1: 166-170.

12 Hutchinson A, Johnson MJ, Currow D. Acute-on-chronic breathlessness: recognition and response. J Pain Symptom Manage 2019; 57: e4-e5.

13 Ahmadi Z, Sandberg J, Shannon-Honson A, et al. Is chronic breathlessness less recognized and treated compared with chronic pain? A case-based randomised controlled trial. Eur Respir J 2018; 52: 1800887.

14 Carette H, Zysman M, Morelot-Panzini C, et al. Prevalence and management of chronic breathlessness in COPD in a tertiary care center. BMC Pulm Med 2019; 19: 95.

15 Hutchinson A, Galvin K, Johnson MJ, et al. "So, I try not to go ..." acute-on-chronic breathlessness and presentation to the emergency department: in-depth interviews with patients, carers, and clinicians. $J$ Pain Symptom Manage 2020; 60: 316-325.

16 Niska R, Bhuiya F, Xu J. National Hospital Ambulatory Medical Care Survey: 2007 Emergency Department Summary. National Health Statistics Reports; no 26. Hyattsville, MD, National Centre for Health Statistics, 2010.

17 Currow DC, Clark K, Mitchell GK, et al. Prospectively collected characteristics of adult patients, their consultations and outcomes as they report breathlessness when presenting to general practice in Australia. PLOS ONE 2013; 8: e74814.

18 Hutchinson A, Pickering A, Williams P, et al. Breathlessness and presentation to the emergency department: a survey and clinical record review. BMC Pulm Med 2017; 17: 53.

19 Kelly AM, Keijzers G, Klim S, et al. An observational study of dyspnea in emergency departments: the Asia, Australia, and New Zealand Dyspnea in Emergency Departments Study (AANZDEM). Acad Emerg Med 2017; 24: 328-336.

20 Laribi S, Keijzers G, van Meer O, et al. Epidemiology of patients presenting with dyspnea to emergency departments in Europe and the Asia-Pacific region. Eur J Emerg Med 2019; 26: 345-349.

21 Kelly AM, Keijzers G, Klim S, et al. Epidemiology and outcome of older patients presenting with dyspnoea to emergency departments. Age Ageing 2021; 50: 252-257.

22 Australian Institute of Health and Welfare. Disparities in Potentially Preventable Hospitalisations across Australia: Exploring the Data. Contract No.: Cat. no. HPF 51. Canberra, AlHW, 2020.

23 Currow DC, Plummer J, Crockett A, et al. A community population survey of prevalence and severity of dyspnoea in adults. J Pain Symptom Manage 2009; 38: 533-545.

24 Taylor A, Dal Grande E, Wilson D. The South Australian Health Omnibus Survey 15 years on: has public health benefited? Public Health Bull (S Aust) 2006; 3: 30-32. 
Currow DC, Del Grande E, Sidhu C, et al. The independent association of overweight and obesity with breathlessness in adults. A cross-sectional, population-based study. Eur Respir J 2017; $50: 1700558$.

Australian Bureau of Statistics. https://dbr.abs.gov.au/region.html?lyr=ste\&rgn=4 Date last accessed: 23 September 2021.

Bestall JC, Paul EA, Garrod R, et al. Usefulness of the Medical Research Council (MRC) dyspnoea scale as a measure of disability in patients with chronic obstructive pulmonary disease. Thorax 1999; 54: 581-586.

Currow DC, Chang S, Reddel H, et al. Breathlessness, anxiety, depression and function - the BAD-F study: a cross-sectional, population prevalence study in adults. J Pain Symptom Manage 2020; 59: 197-205.e2.

Figarska SM, Boezen HM, Vonk JM. Dyspnea severity, changes in dyspnea status and mortality in the general population: the Vlagtwedde/Vlaardingen study. Eur J Epidemiol 2012; 27: 867-876.

Australian Bureau of Statistics. Socio-Economic Indexes for Areas: Finer Levels of Socio-Economic Summary Measures, Cat no.1352.0.55.135. Canberra, Australia, 2013.

World Health Organisation. Obesity and overweight. www.who.int/news-room/fact-sheets/detail/obesity-andoverweight Date last accessed: 9 September 2021. Date last updated: 9 June 2021.

Gilthorpe MS, Jiang T, Tilling K, et al. Common statistical errors: over-adjustment for confounders and mediators in lifecourse research. Int J Epidemiol 2015; 44: suppl_1, i36-i37.

Schisterman EF, Cole SR, Platt RW. Over adjustment bias and unnecessary adjustment in epidemiologic studies. Epidemiology 2009; 20: 488-495.

Organisation for Economic Co-operation and Development. Health Care Utilisation. ECD. https://stats.oecd. org/Index.aspx?DataSetCode=HEALTH_PROC Date last accessed: 25 July 2021.

Banks I. No man's land: men, illness, and the NHS. BMJ 2001; 323: 1058-1060.

Galdas PM, Cheatwer F, Marshall P. Men and health help-seeking behaviour: literature review. J Adv Nursing 2005; 49: 616-623.

Briscoe ME. Why do people go to the doctor? Sex differences in the correlates of GP consultation. Soc Sci Med 1987; 25: 507-513.

Wang Y, Hunt K, Nazareth I, et al. Do men consult less than women? An analysis of routinely collected UK general practice data. BMJ Open 2013; 3: e003320.

Marmot M. Social determinants of health inequalities. Lancet 2005; 365: 1099-1104.

Newman L, Baum F, Harris E. Federal, state and territory government responses to health inequities and the social determinants of health in Australia. Health Prom J Aust 2006; 17: 217-225.

Marmot M, Allen J, Bell R, et al. WHO European review of social determinants of health and the health divide. Lancet 2012; 380: 1011-1029.

2 Adaba P, McGhee SM, Hedley AJ, et al. Smoking, respiratory disease and health service utilisation: the paradox. Soc Sci Med 2005; 60: 483-490.

García-Polo C, Alcázar-Navarrete B, Ruiz-Iturriaga LA, et al. Factors associated with high healthcare resource utilisation among COPD patients. Respir Med 2012; 106: 1734-1742.

4 Oostenbrink JB, Rutten-van Mölken MP. Resource use and risk factors in high-cost exacerbations of COPD. Respir Med 2004; 98: 883-891.

Hart JT. The Inverse Care Law. Lancet 1971; 297: 405-412.

Hutchinson A, Barclay-Klingle N, Galvin K, et al. Living with breathlessness: a systematic literature review and qualitative synthesis. Eur Respir J 2018; 51: 1701477.

7 Johnson M, Bowden J, Abernethy AP, et al. To what causes do people attribute their chronic breathlessness? A population survey. J Palliat Med 2012; 15: 744-750.

8 Skarshaug LJ, Svedahl ER, Bjorngaard JH, et al. Contact with primary health care physicians before an acute hospitalisation. Scand J Prim Health Care 2019; 37: 283-293.

9 Spencer C. M2 A study of the prevalence of respiratory morbidity in the Maasai people living in the rural areas of Kajiado district, Kenya. Thorax 2018; 73: A246.

5 Shipman C, White S, Gysels M, et al. Access to care in advanced COPD: factors that influence contact with general practice services. Prim Care Respir J 2009; 18: 273-278.

51 Elliott-Button HL, Johnson MJ, Nwulu U, et al. Identification and assessment of breathlessness in clinical practice: a systematic review and narrative synthesis. J Pain Symptom Manage 2020; 59: 724-733.

52 Raymond $\mathrm{B}$, Luckett $\mathrm{T}$, Johnson $\mathrm{M}$, et al. Low-intensity educational interventions supporting selfmanagement to improve outcomes related to chronic breathlessness: a systematic review. NPJ Prim Care Respir Med 2019; 29: 41.

53 Currow D, Kochovska S, Ekström M, et al. Request for Modification of WHO ICD-11 (Mortality and Morbidity Statistics) - Public Submission \#238N (Add New Entity Proposal), 2019. https://icd.who.int/dev11/l-m/en

54 Steer J, Norman E, Afolabi O, et al. Dyspnoea severity and pneumonia as predictors of in-hospital mortality and early readmission in acute exacerbations of COPD. Thorax 2012; 67: 117-121.

55 Mitchell KE, Johnson-Warrington V, Apps LD, et al. A self-management programme for COPD: a randomised controlled trial. Eur Respir J 2014; 44: 1538-1547. 